\title{
Article \\ In-Depth Optical Analysis of Zn(Al)O Mixed Metal Oxide Film-Based Zn/Al-Layered Double Hydroxide for TCO Application
}

\author{
Ethar Yahya Salih ${ }^{1, *(\mathbb{D})}$, Asmiet Ramizy ${ }^{2}$, Osamah Aldaghri ${ }^{3}$, Mohd Faizul Mohd Sabri ${ }^{4}\left(\mathbb{D}\right.$, Nawal Madkhali $^{3}$, \\ Tarfah Alinad ${ }^{3}$, Khalid Hassan Ibnaouf ${ }^{3}$ and Mohamed Hassan Eisa ${ }^{3}$
}

check for

updates

Citation: Salih, E.Y.; Ramizy, A.; Aldaghri, O.; Mohd Sabri, M.F.;

Madkhali, N.; Alinad, T.;

Ibnaouf, K.H.; Eisa, M.H. In-Depth Optical Analysis of $\mathrm{Zn}(\mathrm{Al}) \mathrm{O}$ Mixed Metal Oxide Film-Based

Zn/Al-Layered Double Hydroxide for TCO Application. Crystals 2022, 12, 79. https://doi.org/10.3390/ cryst12010079

Academic Editor: Mingjun Huang

Received: 24 November 2021

Accepted: 3 January 2022

Published: 6 January 2022

Publisher's Note: MDPI stays neutral with regard to jurisdictional claims in published maps and institutional affiliations.

Copyright: (C) 2022 by the authors. Licensee MDPI, Basel, Switzerland. This article is an open access article distributed under the terms and conditions of the Creative Commons Attribution (CC BY) license (https:// creativecommons.org/licenses/by/ $4.0 /)$
1 Department of Medical Physics, College of Medical Sciences Techniques, The University of Mashreq, Baghdad 10021, Iraq

2 Physics Department, College of Science, University of Anbar, Anbar 31001, Iraq; asmat_hadithi@uoanbar.edu.iq

3 Department of Physics, College of Sciences, Imam Mohammad Ibn Saud Islamic University (IMSIU), Riyadh 13318, Saudi Arabia; odaghri@imamu.edu.sa (O.A.); namadkhali@imamu.edu.sa (N.M.); tmenad@imamu.edu.sa (T.A.); khiahmed@imamu.edu.sa (K.H.I.); mhsalim@imamu.edu.sa (M.H.E.)

4 NanoMicro Engineering Laboratory, Faculty of Engineering, University of Malaya, Kuala Lumpur 50603, Malaysia; faizul@um.edu.my

* Correspondence: ethar@uom.edu.iq

\begin{abstract}
In this article, an in-depth optical investigation of $\mathrm{Zn}(\mathrm{Al}) \mathrm{O}$-mixed metal oxide (MMO) film using $\mathrm{Zn} / \mathrm{Al}$-layered double hydroxide $(\mathrm{LDH})$ was elucidated through co-precipitation and spin coating techniques. The field emission scanning electron microscopy (FE-SEM) analysis revealed the occurrence of a vertically aligned sheet-like structure with a thickness of $60 \mathrm{~nm}$ for pristine LDH, which further reduced to $45 \mathrm{~nm}$ after calcination at $300{ }^{\circ} \mathrm{C}$. Additionally, pristine $\mathrm{LDH}$ showed multiple optical bandgaps of 5.18, 3.6, and $3.2 \mathrm{eV}$. Moreover, a good agreement of the obtained optical bandgaps was attained between both utilized methods, ultraviolet-visible light (UV-Vis), and photoluminescence (PL) spectroscopies. The optical bandgap decreased at higher calcination temperatures, which indicates the active role of the applied post-fabrication process on the optical profile of the deposited MMO film/s. The demonstrated transmittance spectra of the deposited MMO films exhibited a transparency between $85 \%$ and $95 \%$; this indicates the usefulness and consistency of the proposed film for transparent conductive oxide (TCO) based optoelectronic applications.
\end{abstract}

Keywords: mixed metal oxide; layered double hydroxide; TCO; transmittance; optical bandgap

\section{Introduction}

To date, TCO films have been extensively applied in a number of applications such as solar cells, diodes, photodetectors, etc. owing to their attractive optical and electrical behavior [1-4]. Several TCO films containing impurities such as $\mathrm{ZnO}, \mathrm{In}_{2} \mathrm{O}_{3}$, and $\mathrm{SnO}_{2}$ have been investigated [5-8]. ZnO film, in particular, is widely accepted as the most protuberant material in TCO applications due to its wide optical band gap (3.3 eV), high exciton binding energy, and electron mobility and intrinsic electrical conductivity $\left(\sim 10 \times 10^{-7} \mathrm{~S} / \mathrm{cm}\right)[9]$. $\mathrm{ZnO}$ film, however, repeatedly demands improvements in terms of the aforementioned features, which in turn are achieved through doping; this can be attained through the creation of electronic defects as well as impurities. As such, numerous efforts have been conducted to overcome the addressed $\mathrm{ZnO}$ enhancement demands, wherein $\mathrm{ZnO}$ film is doped with more than a few elements; for instance, Ce, B, Al, Ga, In, etc. [10-15]. Among these, $\mathrm{ZnO}$ doped with $\mathrm{Al}$ has exhibited thought provoking features in optoelectronic applications [16]. Furthermore, Al-doped $\mathrm{ZnO}$, other materials, and film also revealed high dependence on the utilized preparation/deposition method $[2,3,17]$. This is particularly due to the occurrence of undesirable contaminations and uncontrolled defects, which in turn 
result in a lack of reproducibility and robustness of the target TCO application. Furthermore, the introduction of a rapid, cost-effective, highly controlled, and environmentally friendly approach is of importance.

LDH nanoparticles, known as inorganic anionic clays, are a class of 2D nano-layers with the chemical formula $\left[\mathrm{M}_{1-\mathrm{x}}^{2+} \mathrm{M}_{\mathrm{x}}^{3+}(\mathrm{OH})_{2}\right] \mathrm{A}_{\mathrm{x} / \mathrm{m}}^{\mathrm{m}} \cdot \mathrm{nH}_{2} \mathrm{O}$. The $\mathrm{M}^{2+}$ and $\mathrm{M}^{3+}$ are the divalent and trivalent ions, respectively [18]; $\mathrm{Zn}^{2+}$ and $\mathrm{Al}^{3+}$ in our case. Herein, the discussed contamination and defects can be controlled through $\mathrm{Zn}^{2+}$ to $\mathrm{Al}^{3+}$ molar ratio alteration within the LDH structure [19]. In addition, thermal calcination of LDH results in the 2D layers' diminishment and the continuous formation of MMO structure, which consists of metal oxide and spinel phases [20]. The MMO formation has demonstrated a great attraction within research societies in many applications such as dye-sensitized solar cell [21], photodetector [22,23], and gas sensor [24,25], etc. The calcination temperature has great influence on the acquired MMO's properties, wherein its optical behavior was found to be potentially affected [26].

In conjunction, this manuscript aims to present an in-depth investigation of the optical and electrical analysis of $\mathrm{Zn}(\mathrm{Al}) \mathrm{O}-\mathrm{MMO}$ derived from $\mathrm{Zn} / \mathrm{Al}-\mathrm{LDH}$ precursor as a function of a calcination temperature $\left(200,300,400\right.$, and $\left.500^{\circ} \mathrm{C}\right)$. It was found that the alteration in the calcination temperature could influence the optical and electrical properties of MMO films, evidencing a primary potential of MMO film based TCO for optoelectronic applications.

\section{Materials and Methods}

Materials used in this study, including $\mathrm{Al}\left(\mathrm{NO}_{3}\right)_{3} \cdot 9 \mathrm{H}_{2} \mathrm{O}(99.4 \%$, CAS no. 7784-27-2), $\mathrm{Zn}\left(\mathrm{NO}_{3}\right)_{2} \cdot 6 \mathrm{H}_{2} \mathrm{O}$ (98.1\%, CAS no. 10196-18-6), and $\mathrm{NaOH}$ (99\%, CAS no. 1310-73-2) were supplied by Sigma-Aldrich (Selangor, Malaysia). Polyethylene glycol 400 (PEG, CAS no. 25322-68-3) and fluorine-doped tin oxide (FTO) were obtained from LGC Scientific (Selangor, Malaysia) and Solaronix (Aubonne, Switzerland), respectively. Deionized water was utilized in the synthesis of $\mathrm{Zn} / \mathrm{Al}-\mathrm{LDH}$ as a solvent.

In a typical procedure, $\mathrm{Zn}\left(\mathrm{NO}_{3}\right)_{2} \cdot 6 \mathrm{H}_{2} \mathrm{O}$ was mixed with $\mathrm{Al}\left(\mathrm{NO}_{3}\right)_{3} \cdot 9 \mathrm{H}_{2} \mathrm{O}$ in $150 \mathrm{~mL}$ of deionized water using a co-precipitation approach, considering a molar ratio of $6: 1\left(\mathrm{Zn}^{2+}\right.$ to $\left.\mathrm{Al}^{3+}\right)$. This was exhibited under a constant stirring rate of $700 \mathrm{rpm}$ for almost $30 \mathrm{~min}$ at room temperature. A homogeneous crystal growth of $\mathrm{Zn} / \mathrm{Al}-\mathrm{LDH}$ ( $\mathrm{pH} 7.5$ ) was sustained via $\mathrm{NaOH}(1.25 \mathrm{M})$ dropwise addition during the experimental procedure. The attained white slurry precipitate was subsequently retained in an air oven at $60^{\circ} \mathrm{C}$ overnight. The final product was then continuously multi-washed, centrifuged, and later dried at $75^{\circ} \mathrm{C}$.

In order to provide $\mathrm{Zn}(\mathrm{Al}) \mathrm{O}-\mathrm{MMO}$ material, $1 \mathrm{gm}$ of the obtained $\mathrm{LDH}$ product was liquefied in PEG-400, $0.1 \mathrm{gm}$, and few drops of ethanol; the latter was applied to attain a desirable viscosity control. The resultant mixture was deposited onto a clean FTO substrate using multi-cycle spin coating technique ( 3 cycles) to form a $1 \mathrm{~cm}^{2}$ multilayer film. Subsequent to each cycle, the obtained layer was washed and then dried at $65^{\circ} \mathrm{C}$. Hereinafter, the fabricated LDH films were calcined at different calcination temperatures $\left(200,300,400\right.$, and $\left.500{ }^{\circ} \mathrm{C}\right)$ with a heating rate of $5{ }^{\circ} \mathrm{C} / \mathrm{min}$ in air. The obtained products were denoted as T-200, T-300, T-400, and T-500.

The X-ray diffraction was recorded on an XRD diffractometer (AXS D8, Bruker, Beijing, China) under $40 \mathrm{kV}$ and $\mathrm{CuK} \alpha$ radiation. The surface morphology investigation was accomplished via FE-SEM (SU8030, Hitachi, Tokyo, Japan) at an acceleration voltage of $1.20 \mathrm{kV}$. The deposited films' thicknesses ( 500 nm) were recorded on profile-meter P10TENCOR (Milpitas, CA, USA). In the meantime, the optical analyses were conducted using a UV-Vis-NIR spectrophotometer (UV-3600, Shimadzu, Kyoto, Japan). Further optical bandgap investigation was achieved via a room temperature PL spectrometer (LS-50B, Kansas City, MO, USA). Finally, the electrical behavior of the deposited layers was tested using a 4-point probe technique (Jandel, Leighton Buzzard, UK). 


\section{Results and Discussion}

Figure 1 shows the XRD patterns of the synthesized Zn/Al-LDH, in which three pronounced peaks were obtained: (003), (006), and (009). This exhibition confirms the attainment of LDH structure in accordance with the JCPDS data report (38-0486). An additional peak was perceived at $2 \theta 34^{\circ}$, which can be indexed to the existence of $\mathrm{ZnO}$ phase. Figure 1 also shows the XRD patterns of calcined $\mathrm{Zn}(\mathrm{Al}) \mathrm{O}$ film based MMO structure, through which the diminishment of LDH structure had occurred. Specifically, trinary crystal growth (patterns) was observed subsequent to the calcination process of LDH; this can be indexed independently to the hexagonal $\mathrm{ZnO}$ structure (05-0669, JCPDS data report). The existence of comparatively weak peaks such as (102), (103), (104), and (004) indicate that $\mathrm{Al}^{3+}$ did not result in structural changes in the MMO matrix [27]. Further, there is no appearance of $\mathrm{Al}$ and/or $\mathrm{Al}$ oxide, which confirms that ions of $\mathrm{Al}^{3+}$ substituted $\mathrm{Zn}^{2+}$ ions within the MMO matrix.

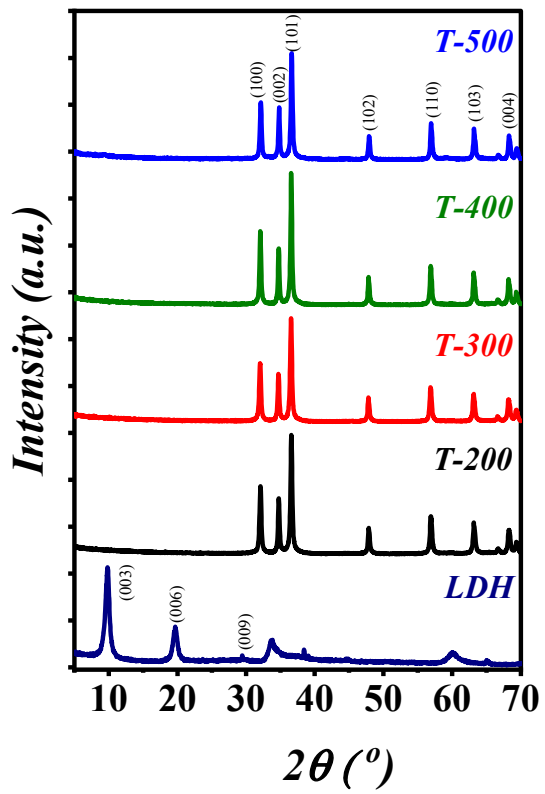

Figure 1. XRD patterns of pristine $\mathrm{LDH}$ and the $\mathrm{MMO}$ at different calcination temperatures.

Figure 2 depicts the obtained FE-SEM micrographs of pristine LDH and the calcine product at $400{ }^{\circ} \mathrm{C}$; inset in the figure is the related EDX. The deposited LDH layer proved the occurrence of a vertically aligned sheet-like structure, which is compacted onto the employed FTO substrate with an average thickness of $60 \mathrm{~nm}$ (Figure 2a). In the meantime, Figure $2 \mathrm{~b}$ revealed that the vertically aligned sheet-like structure was preserved after the calcination process at $300^{\circ} \mathrm{C}$; the latter demonstrated a sheet-like thickness of $45 \mathrm{~nm}$.
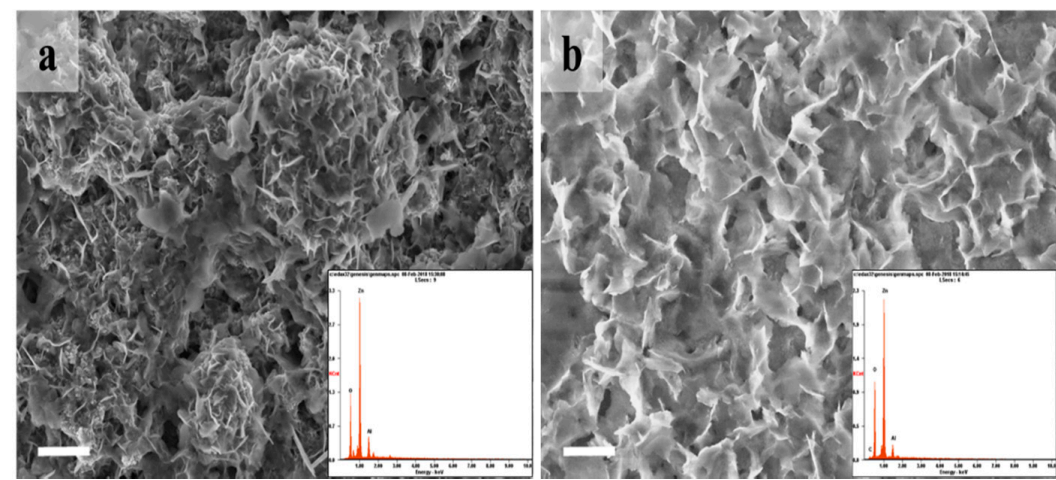

Figure 2. FE-SEM micrographs of (a) pristine LDH and (b) sample obtained at $300{ }^{\circ} \mathrm{C}$ calcination; scale bar of $1 \mu \mathrm{m}$. 
Figure 3a elucidates the absorbance and transmittance spectra of pristine LDH. The absorbance spectrum showed clear multiple absorbance trends at around 240, 290, and $385 \mathrm{~nm}$. Specifically, obtained peaks at around 240 and $290 \mathrm{~nm}$ are attributed to the $\mathrm{CO}_{3}$ existence within the pristine LDH interlayers, whereas the peak at around $385 \mathrm{~nm}$ is mainly due to the direct transition between $n p$ or $n s$ orbitals and $2 p$ orbital ( $\mathrm{n}=4$ for $\mathrm{Zn}$ ) [28]. The transmittance spectrum, on the other hand, demonstrated a similar phenomenon yet an opposite trend to the aforementioned absorbance spectrum; an average transparency of $80 \%$ in the visible region. Moreover, the energy bandgap of the addressed film was calculated according to the Tauc relation [29]:

$$
(\alpha h v)=A\left(h v-E_{g}\right)^{1 / 2}
$$

herein, $\alpha$ is the absorption coefficient, $A$ is the constant value while $h v$ denotes the energy of the photon, and $E_{g}$ is the energy bandgap. Three energy bandgaps $(5.18,3.6$, and $3.2 \mathrm{eV})$ were noticed (Figure $3 b$ ), which can be attributed to the formation of multiple phases, as demonstrated in the XRD analysis. This is reflected throughout the absorbance spectra findings. The refractive index, which is a measure of spectral dispersion and the extinction coefficient, is calculated according to Equations (2) and (3), respectively [9,30]:

$$
\begin{gathered}
n=\frac{1}{T}+\left(\frac{1}{T_{s}}-1\right)^{1 / 2} \\
k=\frac{\alpha \lambda}{4 \pi}
\end{gathered}
$$

where $T$ is the transmittance while $T_{S}$ is given by $\left(10^{-\mathrm{A}}\right) \times 100$, in which $A$ is the absorbance. In the meantime, the optical conductivity, which represents the electronic state of the deposited film, is obtained using the following relation, where $c$ represents the speed of light:

$$
\sigma(o p t .)=\frac{\alpha n c}{4 \pi}
$$

Synchronically, Figure $3 \mathrm{c}$ shows the attained variation of $n$ and $k$ for pristine LDH. The $n$ values exhibited a dramatic decrease profile before being further increased in the UV region, which indicates a desirable optical performance in the mentioned region. This behavior was not observed in the visible light region. The wavelength dependency for the acquired $k$ values revealed quite an opposite profile to that obtained for $n$. In detail, a noticeable decrease was observed at a low wavelength followed by increments in the UV region; the latter was found to be in good agreement with the demonstrated $n$ profile. The optical conductivity in Figure $3 \mathrm{~d}$ tended to continuously increase alongside the photon energy increment; this can be explained through the demonstrated $n$ profile in relation to Equation (4). Consequently, the basic electron excitation spectra of the deposited materials can be elaborated using the complex electronic dielectric constant, $\varepsilon(\omega)$ as a function of frequency dependence. The $\varepsilon$ consists of two parts; namely, real $\left(\varepsilon_{1}(\omega)\right)$ and imaginary $\left(i \varepsilon_{2}(\omega)\right)$ dielectric constants. The $\varepsilon_{1}$ and $\varepsilon_{2}$ are calculated using Equations (5) and (6), respectively [31].

$$
\begin{gathered}
\varepsilon_{1}=n^{2}-k^{2} \\
\varepsilon_{2}=2 n k
\end{gathered}
$$



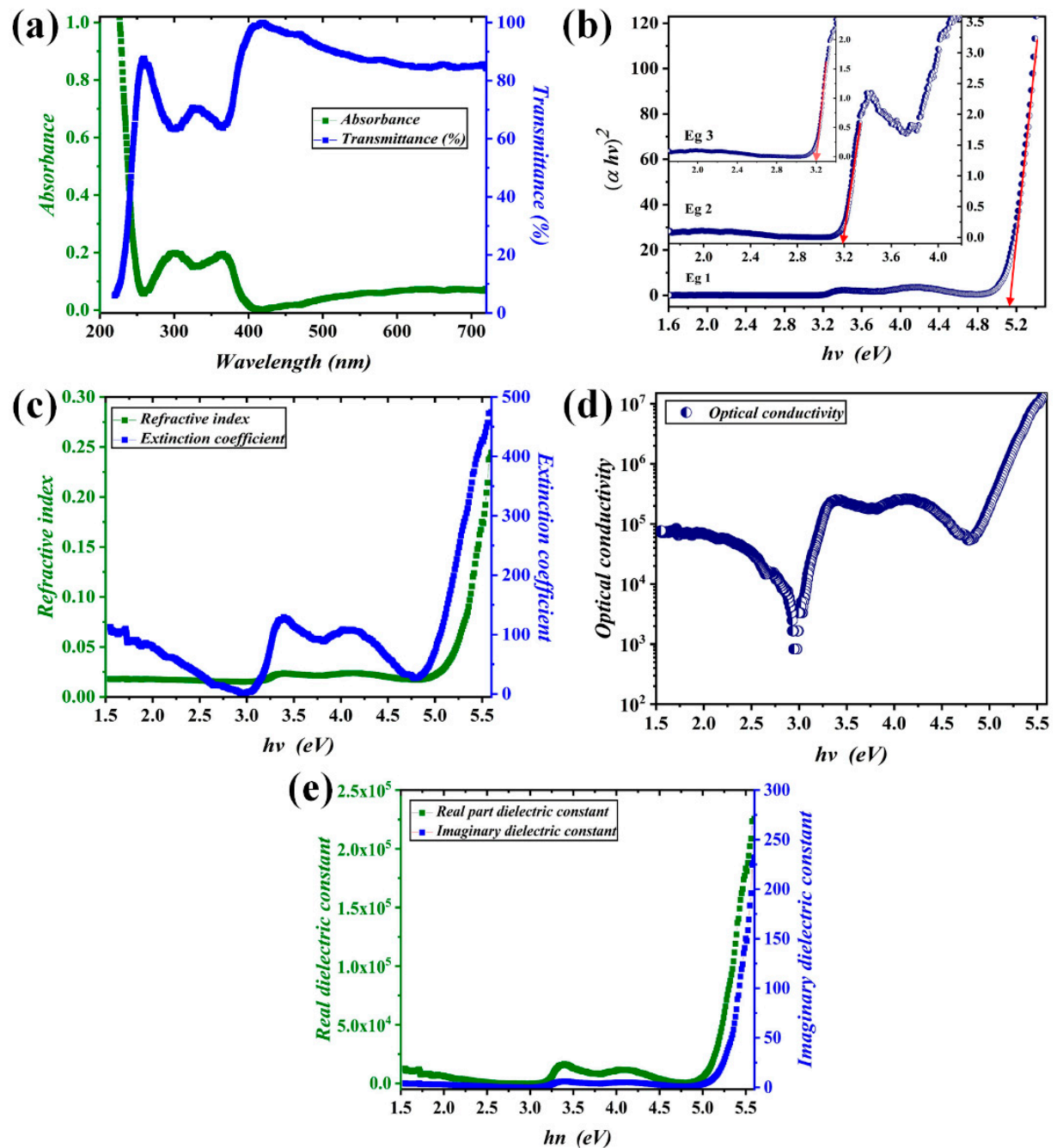

Figure 3. Variation of LDH parameters; (a) absorbance and transmittance, (b) energy band gap, (c) refractive index and extinction coefficient, (d) dielectric constant, and (e) optical conductivity.

Hereinafter, Figure $3 \mathrm{e}$ illustrates the attained $\varepsilon_{1}$ and $\varepsilon_{2}$ values as a function of wavelength. Values of $\varepsilon_{1}$ and $\varepsilon_{2}$ tended to have a high value in the UV region compared to the visible region. This was noticed alongside the higher value of the real part than the imaginary part. The demonstrated profile was found to be similar to previous reports concerning the deposition of bare $\mathrm{ZnO}$ film [9].

Figure 4 presents an optical validation of the deposited films at different calcination temperatures. A noticeable cut-off phenomenon for all films, in the optical absorbance spectra, was preserved at around $380 \mathrm{~nm}$ (Figure 4a). However, there is a slight bathochromic shift (redshift) in the presented absorbance curves, as indicated in the figure. This was noticed alongside a hyperchromic shift throughout the UV region. All deposited films continuously revealed transmittance spectra with almost similar behavior throughout the scanned wavelength (Figure $4 \mathrm{~b}$ ). A pronounced alteration in the transmittance amount ranging between $85-95 \%$ was acquired, with respect to the calcination temperature; this in turn responds well to a considerable TCO criteria [32]. A digital photograph is demonstrated in Figure 5, which indicates a sizeable transparency of the deposited T-400 film; the lowest transmittance value. The fabricated films demonstrate considerable anode materials property for optoelectronic applications through the obtained transparency, which in turn may result in enhanced photon energy absorption onto the active layer in the addressed application. The optical bandgaps of the deposited films are elucidated in Figure 4c,d using UV-Vis and PL techniques, respectively; the former was estimated using the Tauc relation [29] while the latter was evaluated directly from the PL spectra. In detail, a reduction 
in the optical bandgap values was observed, inset in Figure 4c, as the calcination temperature increased, before being further increased at T-500. Similar behavior was noticed in Figure $4 \mathrm{~d}$, with respect to the optical bandgap values. Further, the attained calcined layers demonstrated lower optical band gap values compared to those observed in the pristine sample (Figure $3 b$ ).
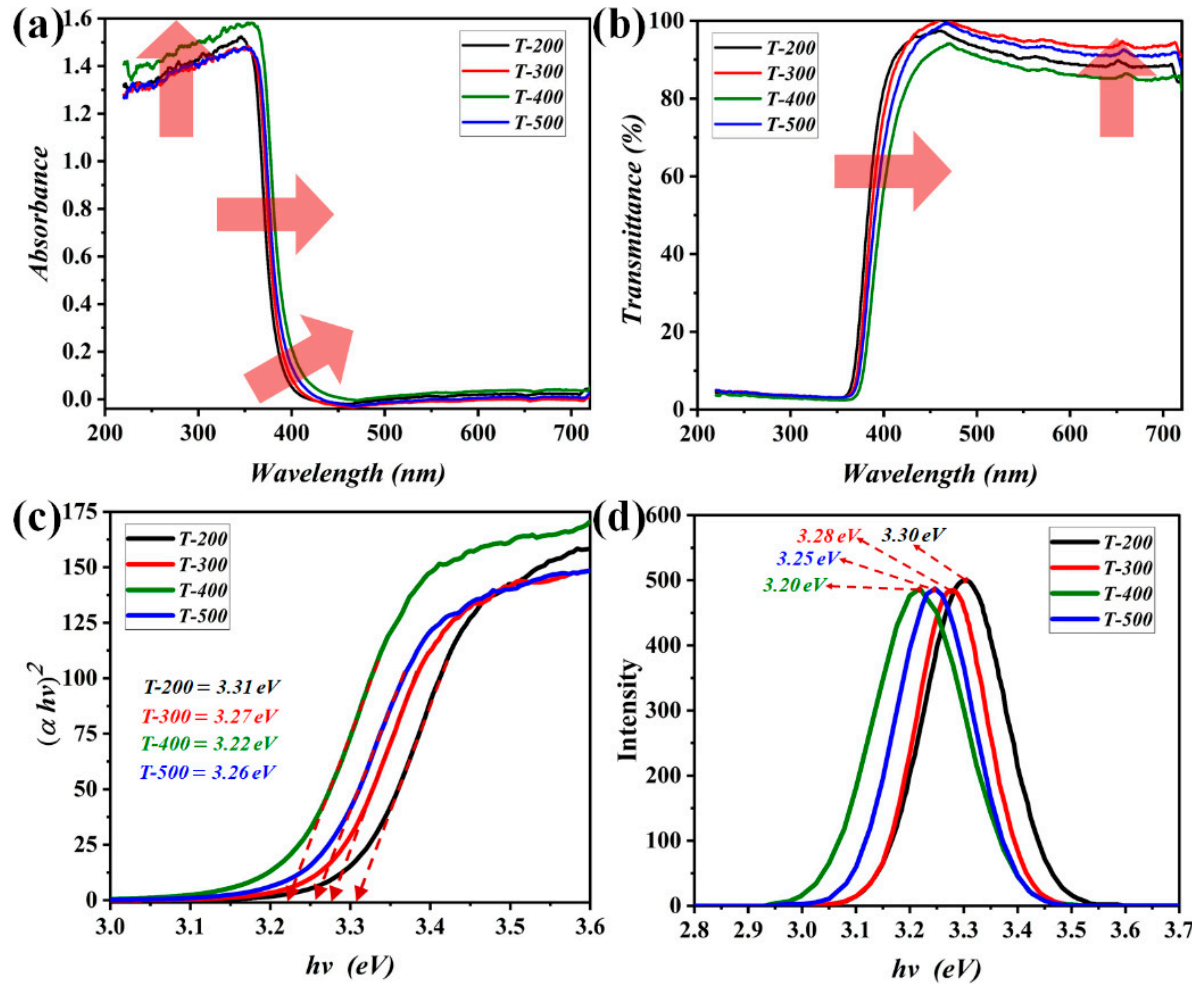

Figure 4. Optical validation for (a) absorbance, (b) transmittance (\%), (c) energy bandgap, and (d) PL spectra of the deposited films.

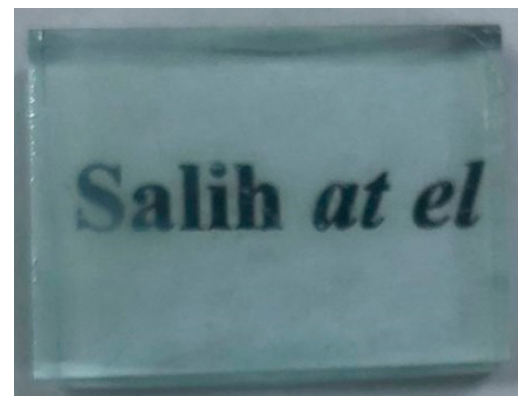

Figure 5. Digital image of the fabricated T-400 MMO film.

The skin depth (the so-called optical penetration depth) provides information about the length through which electromagnetic radiation may penetrate into a material layer. The optical penetration depth can be obtained through the equation $(\delta=1 / \alpha)$, where $\alpha$ is the absorption coefficient. Figure 6 elucidates variation of the transmittance, optical conductivity, and skin depth of the deposited films as a function of calcination temperature. It can be clearly observed that the obtained transmission and skin depth exhibited an exact behavior, which validates the applicability of the fabricated film $/ \mathrm{s}$ as TCO criteria. It can also be noticed that the highest transparency was attained at a calcination temperature of $300^{\circ} \mathrm{C}$. The optical conductivity showed an opposite behavior to those obtained in the transmittance and skin depth profiles. 


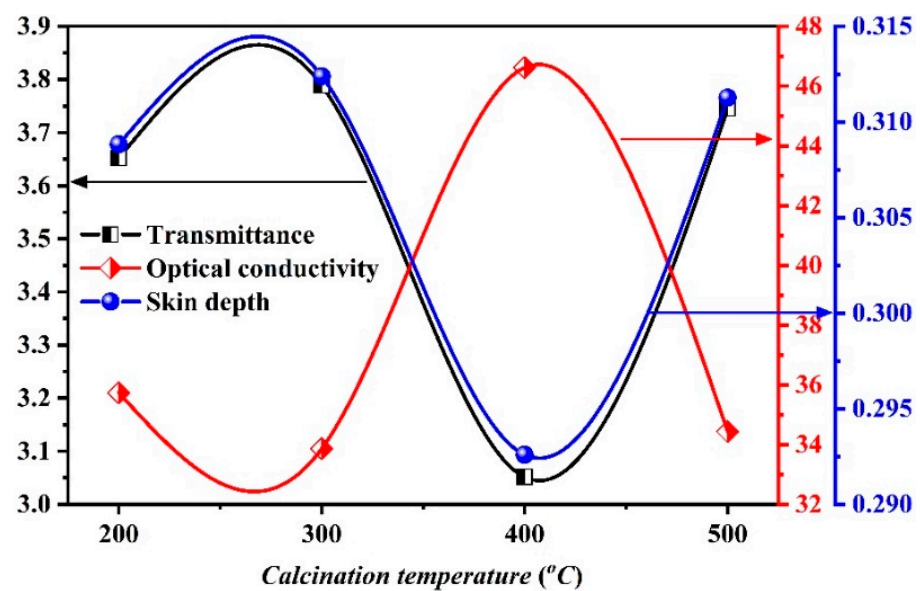

Figure 6. Variation of transmittance, optical conductivity $\left(\times 10^{7}\right)$, and skin depth at a wavelength of $385 \mathrm{~nm}$ as a function of calcination temperature.

Figure 7a represents the attained $n$ of the deposited films at various calcination temperatures, which reveals similar findings to the ones obtained in the optical band gap analysis. Similarly, Figure $7 \mathrm{~b}$ demonstrates the estimated $k$. Both values of $n$ and $k$ demonstrated higher performance of the layer calcined at $400{ }^{\circ} \mathrm{C}$. It can be observed from Figure $7 \mathrm{a}, \mathrm{b}$ that the relationship between $n$ and $k$ values tended to be proportional, while both mentioned factors seemed to generally increase at a higher $h v$ value. Additionally, the demonstrated samples revealed higher performance in the visible light than the one obtained for the pristine LDH sample (Figure 3c). The $\varepsilon_{1}$ and $\varepsilon_{2}$ are demonstrated in Figure 7 throughout the scanned wavelength. Values of $\varepsilon_{1}$ and $\varepsilon_{2}$ presented similar behavior, in which they increased in the UV region and later decreased in the visible light region ( $400 \mathrm{~nm}$ and above). In terms of the applied calcination temperature, increasing the calcination temperature to $400{ }^{\circ} \mathrm{C}$ resulted in a noticeable increment in the dielectric constant profile, while at $500{ }^{\circ} \mathrm{C}$, a reduction was noticed.
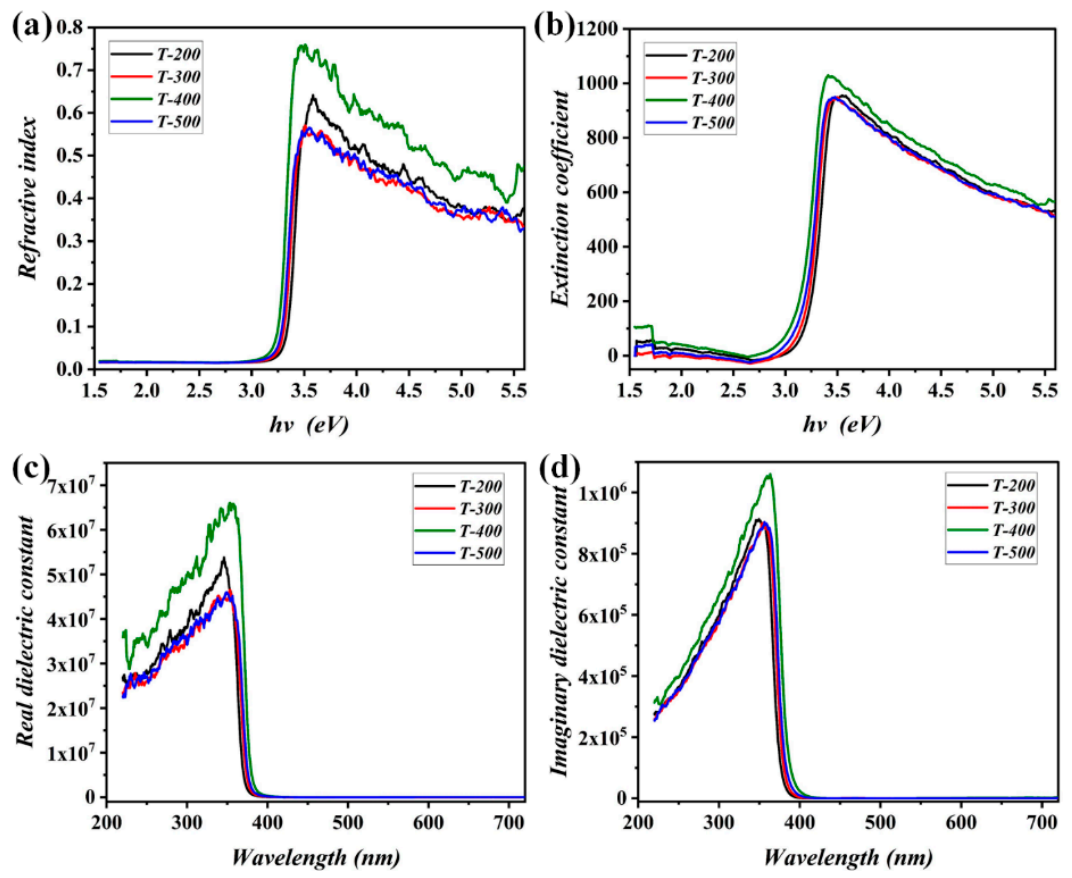

Figure 7. Variation of (a) refractive index, (b) extinction coefficient, (c) real, and (d) imaginary dielectric constant of the deposited film at different calcination temperatures. 
Figure 8 depicts the electrical properties of the deposited films at different calcination temperatures. In this particular investigation, the electrical conductivity of the deposited layers was evaluated as follows [33]:

$$
\begin{gathered}
\sigma=1 / \rho \\
\rho=2 \pi S \times t \times R
\end{gathered}
$$

Herein, $\sigma$ denotes the electrical conductivity $(\mathrm{S} / \mathrm{cm})$, while the resistivity $(\Omega / \mathrm{sq})$ is represented by the symbol $\rho$. In the meantime, $S$ represents the spacing between probes $(0.5 \mathrm{~mm})$ whereas $t$ and $R$ are the layer thickness and measured resistance $(\Omega)$, respectively.

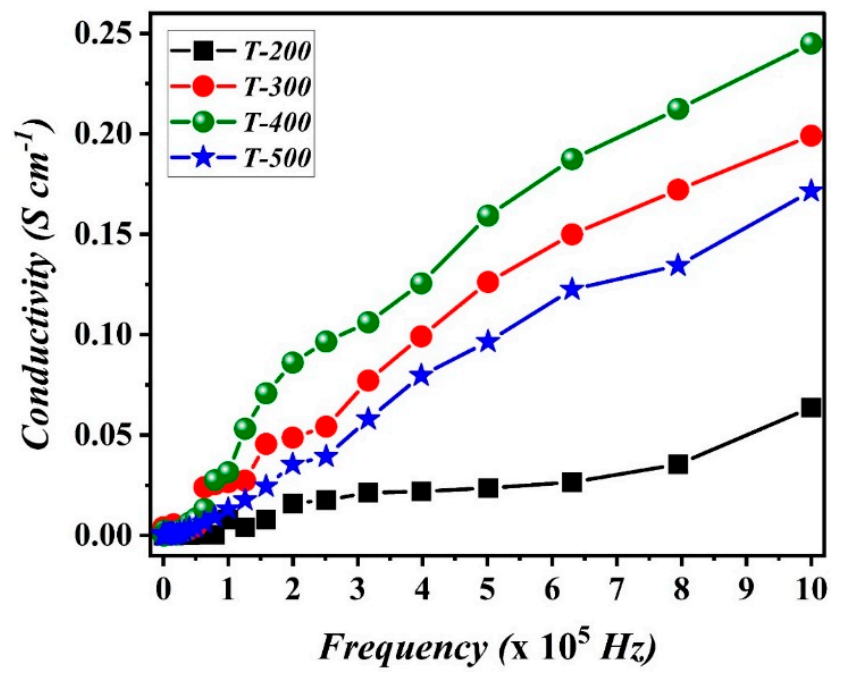

Figure 8. Electrical conductivity of the deposited films at different calcination temperatures.

In general, the demonstrated conductivity trend (Figure 8) shows a total dependency of the estimated electrical conductivity of the deposited layers on the utilized frequency range. As the calcination temperature increased from 200 to $400{ }^{\circ} \mathrm{C}$, a higher conductivity profile of the deposited film was observed. The conductivity outcomes, to a certain extent, agree well with the ones obtained in the optical band gap analysis. This in turn could be understood through the demonstrated optical band gap alignment, wherein higher photoexcitation is attained at a lower optical band gap value. The latter was proven via the conductivity enhancement at a higher calcination temperature. Continuously, Table 1 represents the average resistance, resistivity, and conductivity of the deposited MMO films. It can be clearly seen from the mentioned table that increasing the annealing temperature led to higher conductivity. In comparison to the reported electrical conductivity of nanocrystal $\mathrm{ZnO}\left(7.3 \times 10^{-7} \mathrm{~S} \mathrm{~cm}^{-1}\right)$, the addition of $\mathrm{Al}^{+3}$ in our proposed matrix revealed substantial improvement in the electrical behavior $\left(2.37 \times 10^{-2} \mathrm{~S} \mathrm{~cm}^{-1}\right)$ of MMO films [9]. In the meantime, the highest sheet resistance obtained was found to be $7.43 \times 10^{4} \Omega / \mathrm{sq}$ for $T-400$ film. It was reported that the optimum sheet resistance was found to be $2.4 \times 10^{6} \Omega / \mathrm{sq}$ for a similar matrix using the sol-combustion technique [34]. Meanwhile, the resistivity for TCO ZnO was found to be $2.8 \times 10^{3} \Omega$ /sq using the atomic layer deposition approach [35]. Using the sol-gel method, the optimum sheet resistance of Al-doped $\mathrm{ZnO}$ was reported to be $156 \Omega$ /sq [36].

Table 1. In-depth electrical characteristics of the fabricated MMO films.

\begin{tabular}{cccc}
\hline Sample & Resistance $(\boldsymbol{\Omega})$ & Resistivity $(\boldsymbol{\Omega} / \mathbf{s q})$ & ${\text { Conductivity }\left(\boldsymbol{S} \mathbf{c m}^{-1}\right)}^{-3}$ \\
$T-200$ & $2.37 \times 10^{5}$ & $7.43 \times 10^{4}$ & $4.24 \times 10^{-3}$ \\
$T-300$ & $3.81 \times 10^{3}$ & $1.20 \times 10^{3}$ & $1.87 \times 10^{-2}$ \\
$T-400$ & $6.39 \times 10^{4}$ & $2.01 \times 10^{4}$ & $2.37 \times 10^{-2}$ \\
$T-500$ & $1.11 \times 10^{5}$ & $3.47 \times 10^{4}$ & $1.35 \times 10^{-3}$ \\
\hline
\end{tabular}




\section{Conclusions}

Zn(Al)O-MMO film based Zn/Al-LDH was successfully fabricated on FTO glass substrate using a combination of co-precipitation and spin coating approaches. Subsequently, the effect of post-processing temperature was thoroughly demonstrated via a number of characterization techniques. FE-SEM analysis in particular showed the attainment of vertically aligned sheet-like morphology with an estimated thickness of $45 \mathrm{~nm}$ at an annealing temperature of $300{ }^{\circ} \mathrm{C}$. In the optical bandgap analysis, pristine LDH exhibited multi-oriented optical bandgaps, whereas the post-processing effect resulted in a single average optical bandgap of $3.26 \mathrm{eV}$ in the MMO matrix. The perceived optical transmittance of the post-processed MMO films revealed a considerable transparency, in which transmittance values ranging between $85 \%$ to $95 \%$ were attained. This in turn indicates a potential application of the deposited MMO film for TCO based optoelectronic applications.

Author Contributions: Conceptualization, E.Y.S. and M.F.M.S.; methodology, E.Y.S.; software, E.Y.S.; validation, E.Y.S., A.R. and M.H.E.; formal analysis, E.Y.S.; investigation, E.Y.S., N.M., M.F.M.S. and A.R.; resources, T.A., K.H.I., O.A. and N.M.; data curation, E.Y.S.; writing-original draft preparation, E.Y.S., A.R., T.A. and M.H.E.; writing-review and editing, E.Y.S. and A.R.; visualization, E.Y.S.; supervision, M.F.M.S.; project administration, T.A., N.M., O.A. and K.H.I.; funding acquisition, O.A., T.A., K.H.I. and N.M. All authors have read and agreed to the published version of the manuscript.

Funding: This work was funded by the Deanship of Scientific Research at Imam Mohammad Ibn Saud Islamic University under the Grant (RG-21-09-44).

Data Availability Statement: The data presented in this study are available on request from the corresponding author. The data are not publicly available due to the fact that a foreseeable project is built on the findings of the current data using a simulation framework.

Acknowledgments: The authors express their gratitude to the Deanship of Scientific Research at Imam Mohammad Ibn Saud Islamic University, which funded their work via Research Group no. RG-21-09-44.

Conflicts of Interest: The authors declare no conflict of interest.

\section{References}

1. Cisneros-Contreras, I.; Muñoz-Rosas, A.; Rodríguez-Gómez, A. Resolution improvement in Haacke's figure of merit for transparent conductive films. Results Phys. 2019, 15, 102695. [CrossRef]

2. Abdulkadir, A.; Aziz, A.A.; Pakhuruddin, M.Z. Properties of indium tin oxide on black silicon after post-deposition annealing for heterojunction solar cells. Results Phys. 2020, 19, 103405. [CrossRef]

3. Solaymani, S.; Ţălu, Ş.; Nezafat, N.B.; Dejam, L.; Shafiekhani, A.; Ghaderi, A.; Zelati, A. Optical properties and surface dynamics analyses of homojunction and hetrojunction Q/ITO/ZnO/NZO and Q/ITO/ZnO/NiO thin films. Results Phys. 2021, $29,104679$. [CrossRef]

4. Li, X.; Liu, W.; Li, P.; Song, J.; An, Y.; Shen, J.; Wang, S.; Guo, D. A self-powered nano-photodetector based on PFH/ZnO nanorods organic/inorganic heterojunction. Results Phys. 2018, 8, 468-472. [CrossRef]

5. Kim, J.-H.; Seong, T.-Y.; Chung, K.-B.; Moon, C.S.; Noh, J.H.; Seok, H.-J.; Kim, H.-K. Transparent Sn-doped In2O3 electrodes with a nanoporous surface for enhancing the performance of perovskite solar cells. J. Power Sources 2019, 418, 152-161. [CrossRef]

6. Yu, S.; Zhao, L.; Liu, R.; Wu, M.; Sun, Y.; Li, L. Electrical properties of bulk and interface layers in Sb doped SnO2 thin films. Ceram. Int. 2018, 45, 2201-2206. [CrossRef]

7. Jang, J.S.; Kim, J.; Ghorpade, U.; Shin, H.H.; Gang, M.G.; Park, S.D.; Kim, H.-J.; Lee, D.S.; Kim, J.H. Comparison study of ZnO-based quaternary TCO materials for photovoltaic application. J. Alloy. Compd. 2019, 793, 499-504. [CrossRef]

8. Amoupour, E.; Hasanzadeh, J.; Ziabari, A.A.; Azimi, P. Improving the performance of cadmium telluride-based solar cells using $\mathrm{ZnCdS} / \mathrm{NiO}$ and $\mathrm{ZnO}$ compounds for ETL/HTL and TCO layers. J. Intell. Proced. Electr. Technol. 2021, 81-90.

9. Caglar, M.; Ilican, S.; Caglar, Y.; Yakuphanoglu, F. Electrical conductivity and optical properties of ZnO nanostructured thin film. Appl. Surf. Sci. 2009, 255, 4491-4496. [CrossRef]

10. Bechambi, O.; Touati, A.; Sayadi, S.; Najjar, W. Effect of cerium doping on the textural, structural and optical properties of zinc oxide: Role of cerium and hydrogen peroxide to enhance the photocatalytic degradation of endocrine disrupting compounds. Mater. Sci. Semicond. Process. 2015, 39, 807-816. [CrossRef]

11. Muchuweni, E.; Sathiaraj, T.; Nyakotyo, H. Effect of gallium doping on the structural, optical and electrical properties of zinc oxide thin films prepared by spray pyrolysis. Ceram. Int. 2016, 42, 10066-10070. [CrossRef] 
12. Wahab, S.A.A.; Matori, K.A.; Ab Aziz, S.H.; Zaid, M.H.M.; Kechik, M.M.A.; Azman, A.Z.K.; Khaidir, R.E.M.; Khiri, M.Z.A.; Effendy, N. Effect of $\mathrm{ZnO}$ on the phase transformation and optical properties of silicate glass frits using rice husk ash as a SiO2 source. J. Mater. Res. Technol. 2020, 9, 11013-11021. [CrossRef]

13. Ali, I.; Kashyout, A.E.-H.B.; Tayel, M.; Hassan, H.S.; Rizk, M. Ruthenium (Ru) doped zinc oxide nanostructure-based radio frequency identification (RFID) gas sensors for NH3 detection. J. Mater. Res. Technol. 2020, 9, 15693-15704. [CrossRef]

14. Cai, Z.; Kim, K.-K.; Park, S. Room temperature detection of $\mathrm{NO}_{2}$ gas under UV irradiation based on Au nanoparticle-decorated porous $\mathrm{ZnO}$ nanowires. J. Mater. Res. Technol. 2020, 9, 16289-16302. [CrossRef]

15. Bashir, M.B.A.; Sabri, M.F.M.; Said, S.M.; Miyazaki, Y.; Badruddin, I.A.; Shnawah, D.A.A.; Salih, E.Y.; Abushousha, S.; Elsheikh, M.H. Enhancement of thermoelectric properties of Co4Sb12 Skutterudite by Al and La double filling. J. Solid State Chem. 2020, 284, 121205. [CrossRef]

16. Liu, Y.; Zhu, S.; Song, B. Magnetron sputtering deposition of Zn/AZO multilayer films: Towards the understanding of Zn diffusion in AZO film. Results Phys. 2019, 13, 102286. [CrossRef]

17. Ahmed, N.M.; Sabah, F.A.; Abdulgafour, H.; Alsadig, A.; Sulieman, A.; Alkhoaryef, M. The effect of post annealing temperature on grain size of indium-tin-oxide for optical and electrical properties improvement. Results Phys. 2019, 13, 102159. [CrossRef]

18. Bernardo, M.P.; Ribeiro, C. Zn-Al-based layered double hydroxides (LDH) active structures for dental restorative materials. J. Mater. Res. Technol. 2019, 8, 1250-1257. [CrossRef]

19. Gorokhovsky, A.; Tsiganov, A.; Nikityuk, T.; Escalante-Garcia, J.; Burmistrov, I.; Goffman, V. Synthesis and properties of nanocomposites in the system of potassium polytitanate-layered double hydroxide. J. Mater. Res. Technol. 2020, 9, 3924-3934. [CrossRef]

20. Salih, E.Y.; Sabri, M.F.M.; Tan, S.T.; Sulaiman, K.; Hussein, M.Z.; Said, S.M.; Yap, C.C. Preparation and characterization of $\mathrm{ZnO} / \mathrm{ZnAl}_{2} \mathrm{O}_{4}$-mixed metal oxides for dye-sensitized photodetector using $\mathrm{Zn} /$ Al-layered double hydroxide as precursor. J. Nanoparticle Res. 2019, 21, 55. [CrossRef]

21. Wang, C.; Zhu, Y.; Ge, Z.; Shi, R.; Chen, T.; Chen, Z.; Liu, J. The feasible photoanode of graphene oxide/zinc aluminum mixed metal oxides for the dye-sensitized solar cell. Colloid Interface Sci. Commun. 2020, 39, 100313. [CrossRef]

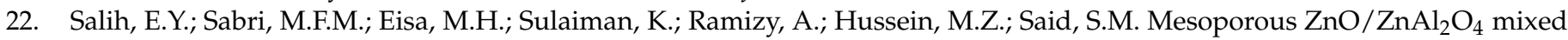
metal oxide-based $\mathrm{Zn} / \mathrm{Al}$ layered double hydroxide as an effective anode material for visible light photodetector. Mater. Sci. Semicond. Process. 2020, 121, 105370. [CrossRef]

23. Salih, E.Y.; Bashir, M.B.A.; Rajpar, A.H.; Badruddin, I.A. Fabrication and characterization of porous $\mathrm{Si} / \mathrm{CuO}$ film for visible light MSM photodetector: The effect of post-processing temperature. Ceram. Int. 2021; in press. [CrossRef]

24. Ramany, K.; Shankararajan, R.; Savarimuthu, K.; Venkatachalapathi, S.; Sivakumar, G.; Murali, D.; Gunasekaran, I. Experimental verification of mixed metal oxide-based sensor for multiple sensing application. Mater. Lett. 2021, 301, 130248. [CrossRef]

25. Mohammed, A.S.; Fahad, O.A.; Ramizy, A.; Salih, E.Y. Thickness effect of $\mathrm{Al}_{2} \mathrm{O}_{3}$ as buffer layer on Alq3 sensitivity for toxic gas. Ceram. Int. 2021, 47, 17907-17914. [CrossRef]

26. Lahkale, R.; Sadik, R.; Elhatimi, W.; Bouragba, F.; Assekouri, A.; Chouni, K.; Rhalmi, O.; Sabbar, E. Optical, electrical and dielectric properties of mixed metal oxides derived from $\mathrm{Mg}$-Al Layered Double Hydroxides based solid solution series. Phys. B Condens. Matter 2021, 413367. [CrossRef]

27. Asemi, M.; Ahmadi, M.; Ghanaatshoar, M. Preparation of highly conducting Al-doped ZnO target by vacuum heat-treatment for thin film solar cell applications. Ceram. Int. 2018, 44, 12862-12868. [CrossRef]

28. Franklin, S.; Balasubramanian, T.; Nehru, K.; Kim, Y. Crystal structure, conformation, vibration and optical band gap analysis of bis [rac-propranolol nitrate]. J. Mol. Struct. 2009, 927, 121-125. [CrossRef]

29. Kumar, V.; Sharma, S.K.; Sharma, T.; Singh, V. Band gap determination in thick films from reflectance measurements. Opt. Mater. 1999, 12, 115-119. [CrossRef]

30. Fakhri, M.; Al-Douri, Y.; Hashim, U.; Salim, E. Optical investigations of photonics lithium niobate. Sol. Energy 2015, 120, 381-388. [CrossRef]

31. Hodgson, J.N. Optical Absorption and Dispersion in Solids; Springer Science \& Business Media: Berlin, Germany, 2012.

32. Beyer, W.; Hüpkes, J.; Stiebig, H. Transparent conducting oxide films for thin film silicon photovoltaics. Thin Solid Films 2007, 516, 147-154. [CrossRef]

33. Topsoe, H. Geometric factors in four point resistivity measurement. Bulletin 1968, 472, 63.

34. Wang, Y.; Xu, M.; Li, J.; Ma, J.; Wang, X.; Wei, Z.; Chu, X.; Fang, X.; Jin, F. Sol-combustion synthesis of Al-doped ZnO transparent conductive film at low temperature. Surf. Coatings Technol. 2017, 330, 255-259. [CrossRef]

35. Beh, H.; Hiller, D.; Zacharias, M. Optimization of ALD-ZnO Thin Films toward Higher Conductivity. Phys. Status Solidi 2018, 215, 1700880. [CrossRef]

36. Das, A.; Das, G.; Kabiraj, D.; Basak, D. High conductivity along with high visible light transparency in Al implanted sol-gel ZnO thin film with an elevated figure of merit value as a transparent conducting layer. J. Alloy. Compd. 2020, 835, 155221. [CrossRef] 